\title{
The Association of Pulmonary Function, Physical Activity, Cardiorespiratory Fitness, Borg Dyspnea Scales and Health Related Quality of Life in Patients With Resected Lung Cancer
}

\author{
Xinping Li \\ Guangdong Provincial People's Hospital \\ Yi Chen \\ Shenzhen Children's Hospital \\ Shuangchun Liu \\ Southern Medical University \\ Mingsheng Zhang ( $D$ mszrch@163.com ) \\ Guangdong Provincial People's Hospital
}

\section{Research Article}

Keywords: Relationship, lung cancer, quality of life, direct effect, cardiorespiratory fitness

Posted Date: July 7th, 2021

DOI: https://doi.org/10.21203/rs.3.rs-543131/v2

License: (c) (i) This work is licensed under a Creative Commons Attribution 4.0 International License.

Read Full License 


\section{Abstract \\ Purpose}

This novel study aims to explore the relationship between pulmonary function, physical activity, cardiorespiratory fitness (CRF), dyspnea, and the health-related quality of life (HRQoL) of patients with resected lung cancer.

\section{Methods}

A cross-sectional study design with 38 lung cancer survivors after surgery for one month was conducted.

We assessed CRF by measuring maximal oxygen consumption $\left(\mathrm{VO}_{2 \max }\right)$ and anaerobic threshold (VT). Forced vital capacity (FVC) was measured using a spirometer. Physical activity, dyspnea, and HRQoL were investigated by 6-minute walking distance (6MWD), Borg dyspnea scales, and the SF-36 Health Survey (SF-36), respectively. Data analyses were conducted using SmartPLS to examine path analyses between the measures.

\section{Results}

There was a significant relationship between CRF and HRQoL in this cohort of cancer survivors. FVC $\left(f^{2}=\right.$ $0.265)$ and $6 \mathrm{MWD}\left(\mathrm{f}^{2}=0.389\right)$ have a medium to large effect size on the perceived CRF while CRF $\left(\mathrm{f}^{2}=\right.$ $0.467)$ was found to have large effect sizes on perceived QoL. More importantly, our results showed that CRF positively and significantly mediated the paths between FVC, 6MWD, and HRQoL [ $\beta=0.22$ $(0.457 \star 0.474), P<0.01 ; \beta=0.28(0.525 * 0.540), P<0.01$; respectively].

\section{Conclusions}

Pulmonary function, physical activity, and dyspnea had an indirect effect on the quality of life in patients with resected lung cancer. Furthermore, CRF mediates pulmonary function and physical activity to produce an impact on their quality of life.

\section{Introduction}

Much progress has been made in the diagnosis and treatment for non-small cell lung cancer in recent years, and the prognosis gradually improves corresponding. For a significant number of patients, surgical resection is the preferred therapeutic method. Unfortunately, the survival rate following an operation is not satisfactory, more and more patients acquire prolonged postoperative survival [1], and improving quality of life (QoL) for those patients is also important [2]. 
lung resection has a significant short- and long-term impact on pulmonary function and oxygenation [3], and physical activities, measured by 6-minute walking distance (6MWD), were also reported to decline after surgery [4]. And many symptoms including dyspnea, emotional, pain, and side effects of treatment may occur after lung resection. Meanwhile, good quality of life after surgery is one of the main goals of comprehensive treatment. However, lung resection is so invasive that it lowers QoL, especially, in the early period after surgical treatment [5]. Unfortunately, a limited number of studies have examined the relationship between pulmonary function, cardiorespiratory fitness (CRF), physical activities, dyspnea, and QoL.

Many pieces of evidence showed that the symptoms are involved in the quality of life. For instance, the previous study showed that there was a strong association between the peak oxygen uptake and 6MWD in adults with achondroplasia [6]. Engberg et al. found that CRT was positively associated with healthrelated QoL in women at risk for gestational diabetes [7]. And Ha D et al. reported that exercise capacity was independently associated with QoL for lung cancer patients after post-curative-intent treatment [8]. Based on those results, we hypothesized that pulmonary function, CRF, physical activities, and dyspnea can influence QoL in patients with resected lung cancer.

Understanding the determinants of QoL for the patients after lung resection would be beneficial to affect the prevention programs and the treatment strategies. In this study, we investigate the association between pulmonary function, CRF, physical activities, dyspnea, and QoL in patients after lung resection and validate our proposed model.

\section{Patients And Methods}

\section{Study design and population}

A cross-sectional study was designed. This study was performed according to the declaration of Helsinki and was approved by the Guangdong provincial people's Hospital.

The patients who underwent a lobectomy or a segmentectomy were recruited following the criteria were non-small-cell lung cancer staged T1, T2, and T3a with or without COPD. The Exclusion factors included: non-small-cell lung cancer staged T3b and T4, associated with other serious chronic diseases; refused to participate in this study.

\section{Protocol}

Each patient had a routine full clinical assessment before the inclusion process, and all patients included in the present study provided written informed consent before data collection. The assessments including QoL, CRF, pulmonary function, physical activities, and dyspnea were performed one month after lung resection. Data were collected from February 2015 to November 2018.

\section{Health-related QoL (HRQoL)}


We assessed HRQoL with a 36-item short-form health survey V1 (SF-36) [9]. The survey is a valid and reliable 36-item questionnaire that is widely used to measure QoL. It yields two summary scores of physical (Physical Functioning, Role-Physical, Bodily Pain, and General Health) and mental (Vitality, Social Functioning, Mental Health, and Role-Emotional) health. The scales range from 0 to 100 , with 0 indicating the worst situation and 100 indicating the best situation in each domain.

\section{CRF}

A physician examined the patients beforehand to ensure their suitability to perform the test. We assessed CRF by measuring maximal oxygen consumption $\left(\mathrm{VO}_{2 \max }\right)$ and anaerobic threshold $(\mathrm{VT})$ in incremental (30W/3min) cycle ergometer exercise (Metamax 3B, Cortex, Germany) until patient fatigue. $\mathrm{VO}_{2 \max }$ was determined as the highest 1-minute average value and was normalized for body mass $\left(\mathrm{mL} \cdot \mathrm{kg}^{-1} \cdot \mathrm{min}^{-1}\right)$.

\section{Pulmonary function}

Pulmonary volumes including forced vital capacity (FVC) and forced expiratory volume at 1 second $\left(\mathrm{FEV}_{1}\right)$ were measured using a spirometer (Electgraph HI-101, CHEST, Tokyo, Japan), and corrected for temperature and barometric pressure, according to the American Thoracic Society recommendations [10]. Each patient performed at least three trials and the best performance was used for analysis. Because QoL had a poor correlation with $\mathrm{FEV}_{1}[11]$, we choose FVC for the statistical analysis.

\section{Physical activities}

Physical activity was determined by 6-MWD [12]. 6-MWD was carried out under the same conditions. Patients were instructed to walk at their fastest pace to cover the longest possible distance over 6 min. The longest walk was taken to represent the value.

\section{Borg dyspnea scale}

Prior to pulmonary function testing, the patients were requested to quantify their sensation of dyspnea by pointing to a score on the Borg scale category ratio 10 (CR10).

\section{Statistical analysis}

Data were expressed as the mean values \pm SD for ordinal or continuous variables, and as numbers and percentages for categorical variables. Statistical analysis was performed using GraphPad Prism software version 8.0 for Windows (GraphPad Software, San Diego, California, USA), and SMARTPLS 3.0 was used to run confirmatory factor analysis (CFA) and to verify the internal consistency, reliability, and validity of the theoretical model. We examined whether the variables were normally distributed with the Andersondarling test, then we used Spearman's correlation coefficients $\left(r_{s}\right)$ for non-normally distributed variables. For normally distributed variables, we used Pearson's correlation coefficients $\left(r_{p}\right)$. Finally, the structural model was estimated and used SmartPLS to examine path analyses between the measures., and the proposed hypotheses were confirmed. 


\section{Results}

\section{Clinical characteristics}

Table 1 summarizes the characteristics, CRF, HRQoL, FVC, 6MWD, and Borg dyspnea scales of the patients. 31 patients underwent a lobectomy, and 7 patients had a segmentectomy. All of the patients did not perform the preoperative treatment, and the TNM classification of the lung cancers were as following: 24 stages 1, 10 stages 2 , and 4 stages 3 a. The types of lung cancer cells were as follows: 22 adenocarcinomas, 13 squamous carcinomas, and 3 others.

Table 1

Thepatients' clinical characteristics and functional variables in patients with lung cancer resection $(n=$ 38)

\begin{tabular}{|llll|}
\hline Variables & Gender/mean \pm & Variables & Mean \pm SD \\
\hline Sex (males/females) & $22 / 16$ & VO2max & $16.95 \pm$ \\
\hline Age, years & & & 4.12 \\
\hline BMI & $63.93 \pm 8.75$ & VT & $11.42 \pm$ \\
& & & 2.87 \\
\hline Smoking history (No/Yes) & $22.33 \pm 2.84$ & 6MWD & $477.3 \pm$ \\
Histological type (Ad/Sc/other) & $28 / 10$ & FVC & 67.92 \\
\hline Pathological stage (I/II/III) & $22 / 13 / 3$ & Borg scales & $1.86 \pm 0.63$ \\
& $24 / 10 / 4$ & HRQoL & $1.07 \pm 0.53$ \\
\hline $\begin{array}{l}\text { Surgery (a lobectomy or a } \\
\text { segmentectomy) }\end{array}$ & $31 / 7$ & Physical Component & $23.52 \pm$ \\
& & Summary & 7.59 \\
& & Mental Component & $27.29 \pm$ \\
\hline
\end{tabular}

\section{Correlation matrix}

The correlation matrix of CRF, FVC, 6MWD, Borg dyspnea scales and HRQoL were shown in Table 2. $\mathrm{VO}_{2 \max }$ and VT were positively associated with 6 out of 8 domain scales of the SF-36. FVC was positively associated with the role-Emotional, vitality, and general health scales of the SF-36. Borg dyspnea scales were negatively associated with the physical functioning, physical functioning, and mental health scales of the SF-36. And 6MWD was positively associated with the physical functioning, mental health, and social functioning scales of the SF-36. 
Table 2

Correlation coefficients of FVC, AT, V02max, 6MWD, and Borg scales with health-related quality of life (SF-36)

\begin{tabular}{|c|c|c|c|c|c|}
\hline Domains & FVC & AT & $\mathrm{VO}_{2 \max }$ & 6MWD & Borg scales \\
\hline $\begin{array}{l}\text { Physical } \\
\text { Functioning }\end{array}$ & $\begin{array}{l}\text { Rs }=0.144, P \\
=0.388\end{array}$ & $\begin{array}{l}\text { Rs }=0.448, P \\
=0.005\end{array}$ & $\begin{array}{l}\text { Rs }=0.474, \mathrm{P} \\
=0.003\end{array}$ & $\begin{array}{l}\text { Rs }=0.427, \mathrm{P} \\
=0.008\end{array}$ & $\begin{array}{l}\text { Rs=-0.346, } P \\
=0.033\end{array}$ \\
\hline Role-Physical & $\begin{array}{l}\text { Rs }=0.185, P \\
=0.266\end{array}$ & $\begin{array}{l}\text { Rs }=0.430, P \\
=0.007\end{array}$ & $\begin{array}{l}\text { Rs }=0.515, \mathrm{P} \\
=0.001\end{array}$ & $\begin{array}{l}\text { Rs }=0.448, P \\
=0.005\end{array}$ & $\begin{array}{l}\text { Rs }=-0.432, P \\
=0.007\end{array}$ \\
\hline Bodily Pain & $\begin{array}{l}\text { Rs }=0.205, \mathrm{P} \\
=\mathbf{0} .217\end{array}$ & $\begin{array}{l}\text { Rs }=0.181, \mathrm{P} \\
=0.277\end{array}$ & $\begin{array}{l}\text { Rs }=0.203, P \\
=0.222\end{array}$ & $\begin{array}{l}\text { Rs }=0.065, \mathrm{P} \\
=0.697\end{array}$ & $\begin{array}{l}\text { Rs }=-0.029, P \\
=0.865\end{array}$ \\
\hline $\begin{array}{l}\text { General } \\
\text { Health }\end{array}$ & $\begin{array}{l}\mathrm{Rp}=0.432, \mathrm{P} \\
=0.0068\end{array}$ & $\begin{array}{l}\mathrm{Rp}=0.047, \mathrm{P} \\
=0.782\end{array}$ & $\begin{array}{l}\mathrm{Rp}=0.254, \mathrm{P} \\
=0.124\end{array}$ & $\begin{array}{l}\mathrm{Rp}=0.137, \mathrm{P} \\
=0.4117\end{array}$ & $\begin{array}{l}\text { Rs }=-0.105, P \\
=0.531\end{array}$ \\
\hline Vitality & $\begin{array}{l}\text { Rs }=0.566, P \\
=0.000\end{array}$ & $\begin{array}{l}\text { Rs }=0.435, P \\
=0.006\end{array}$ & $\begin{array}{l}\text { Rs }=0.393, P \\
=0.015\end{array}$ & $\begin{array}{l}\text { Rs }=-0.065, P \\
=0.700\end{array}$ & $\begin{array}{l}\text { Rs }=0.083, \mathrm{P} \\
=0.621\end{array}$ \\
\hline $\begin{array}{l}\text { Social } \\
\text { Functioning }\end{array}$ & $\begin{array}{l}\text { Rs }=0.123, P \\
=0.461\end{array}$ & $\begin{array}{l}\text { Rs }=0.522, \mathrm{P} \\
=0.001\end{array}$ & $\begin{array}{l}\text { Rs }=0.421, P \\
=0.008\end{array}$ & $\begin{array}{l}\text { Rs }=0.367, \mathrm{P} \\
=0.023\end{array}$ & $\begin{array}{l}\text { Rs=-0.230, } P \\
=0.166\end{array}$ \\
\hline $\begin{array}{l}\text { Mental } \\
\text { Health }\end{array}$ & $\begin{array}{l}\text { Rs }=0.111, P \\
=0.507\end{array}$ & $\begin{array}{l}\text { Rs }=0.368, \mathrm{P} \\
=0.029\end{array}$ & $\begin{array}{l}\text { Rs }=0.334, \mathrm{P} \\
=0.0404\end{array}$ & $\begin{array}{l}\text { Rs }=0.328, P \\
=0.045\end{array}$ & $\begin{array}{l}\text { Rs }=-0.444, P \\
=0.005\end{array}$ \\
\hline $\begin{array}{l}\text { Role- } \\
\text { Emotional }\end{array}$ & $\begin{array}{l}\mathrm{Rp}=0.402, \mathrm{P} \\
=0.0124\end{array}$ & $\begin{array}{l}\mathrm{Rp}=0.369, \mathrm{P} \\
=0.0225\end{array}$ & $\begin{array}{l}\mathrm{Rp}=0.482, \mathrm{P} \\
=0.0022\end{array}$ & $\begin{array}{l}\mathrm{Rp}=0.197, \mathrm{P} \\
=0.2367\end{array}$ & $\begin{array}{l}\text { Rs }=-0.169, \mathrm{P} \\
=0.310\end{array}$ \\
\hline Summary & $\begin{array}{l}\mathrm{Rp}=0.300, \mathrm{P} \\
=0.0672\end{array}$ & $\begin{array}{l}\mathrm{Rp}=0.412, \mathrm{P} \\
=0.0102\end{array}$ & $\begin{array}{l}\mathrm{Rp}=0.490, \mathrm{P} \\
=0.0018\end{array}$ & $\begin{array}{l}\mathrm{Rp}=0.328, \mathrm{P} \\
=0.044\end{array}$ & $\begin{array}{l}\text { Rs }=-0.348, P \\
=0.032\end{array}$ \\
\hline
\end{tabular}

\section{Evaluation of the structural model}

Table 3 and Fig. 1 showed that the hypothesis model was supported and indicated an acceptable model fit. The $\mathrm{R}^{2}$ value for QoL construct is 0.385 which means $38.5 \%$ of the changes in QoL were due to pulmonary function, cardiorespiratory fitness, physical activities, and dyspnea in the model (Fig. 1). The path linking CRF to the perceived QoL was positive and statistically significant, and the path linking FVC, 6MWD, and Borg scales to QoL was not positive and statistically insignificant (Fig. 1). We found that FVC $\left(f^{2}=0.265\right)$ and 6MWD $\left(f^{2}=0.389\right)$ have a medium to large effect size on the perceived CRF while CRF was found to have large effect sizes on perceived QoL (Table 4). 
Table 3

Summary of structural model hypotheses

\begin{tabular}{|c|c|c|c|c|}
\hline Path & Path coefficients & t-value & Sig. & Inference \\
\hline $\mathrm{Dy} \square \mathrm{PC}$ & -0.528 & 5.511 & 0.000 & Supported \\
\hline CRFロQoL & 0.564 & 6.999 & 0.000 & Supported \\
\hline $\mathrm{PC} \square \mathrm{CRF}$ & 0.476 & 3.937 & 0.000 & Supported \\
\hline PFICRF & 0.393 & 3.069 & 0.002 & Supported \\
\hline
\end{tabular}

Table 4

Results of effect size $\mathrm{f}^{2}$ analysis

\begin{tabular}{|lllll|}
\hline Dependent construct & Independent construct & $\mathbf{R}^{\mathbf{2}}$ & $\mathbf{f}^{\mathbf{2}}$ & Inference \\
\hline QoL & CRF & 0.318 & 0.467 & Large \\
\hline CRF & PF & 0.425 & 0.265 & Medium to large \\
\cline { 2 - 4 } & PC & & 0.389 & Large \\
\hline PC & Dy & 0.278 & 0.386 & Large \\
\hline $\begin{array}{l}\text { Dy, dyspnea; PC, physical capacity; CRF, cardiorespiratory fitness; PF, pulmonary function; QoL, quality } \\
\text { of life }\end{array}$ & & & \\
\hline
\end{tabular}

\section{Result for mediation test}

According to the views from Preacher and Hayes [13], the path model for the relationships between physical activities $(\beta=0.441, P<0.05)$, pulmonary function $(\beta=0.462, P<0.05)$, dyspnea $(\beta=0.491, P<$ $0.05)$, and QoL were statistically significant. However, after adjusting the indirect effects of the mediator, the direct effect of physical activities $(\beta=0.045, P>0.05)$, pulmonary function $(\beta=0.190, P>0.05)$ or dyspnea $(\beta=0.19, P>0.05)$ on HRQoL was no longer significant, as shown in Fig. 2 and Supplementary Fig. 1-2. The indirect effects indicate that there is a mediation. Supplementary Fig. 2 depicted that pulmonary function or physical activities was positively related to engagement in CRF, which in turn was significantly related to QoL (Fig. 2, and Supplementary Fig. 2). And Borg scales need to be positively related to physical activities, then significantly related to CRF and QoL (Supplementary Fig. 1).

\section{Discussion}


This study used the path-analyses method to examine the relationship between CRF, FVC, 6MWD, Borg scale, and health-related QoL in patients with lung resection. Our results showed that FVC was poor correlated with QoL. And Bog scales were a strong correlation with physical activities only. Though 6MWD and FVC were positively associated with QoL, an insignificant direct effect between QoL with FVC or 6MWD was observed. Our findings also showed that CRT was a strong correlation with QoL, and took charge of $38.4 \%$ of the changes in the perceived quality of life in the model. CRF as a mediator between Pulmonary function, physical activities, Borg scale, and QOL is novel.

Many pieces of evidence showed that lung resection had a significant impact on respiratory function, and the deficits may reduce the patients' QoL [3, 5]. However, Brunelli et al. found that QoL had a poor correlation with FEV1 and CO lung diffusion capacity [3]. In the present study, we also showed that FVC was not related to QoL. Noting that FVC was positively associated with the general health, vitality, and role-emotional scales of the SF-36, those results indicated that FVC only affected a few functioning scales and could not be taken as surrogates for QOL evaluation [11]. Because the indirect effects from FVC to QoL were observed in our study, pulmonary function-enhancing intervention may be useful in improving quality of life in patients with resected lung cancer.

Wolkove et al. reported that dyspnea is poorly correlated with pulmonary function in patients with obstructive lung disease [14]. In the present study, we found that Borg scales were positively associated with physical activities from our mediation model. Furthermore, the main negative relationship between Borg scales and the domains of the SF-36 was physical functioning and role-physical in this study. And the worsening dyspnea caused patients to reduce their physical activities [15]. Those results indicated that Borg dyspnea scales were preferred to describe the physical status.

Lung cancer survivors always experience QoL impairments, and engagement in physical activity is associated with better QoL. Also, physical activity was independently associated with QoL in lung cancer patients with post-curative-intent treatment [8]. We also found that 6MWD was associated with QoL but the significance level was $P=0.044$. However, $6 \mathrm{MWD}$ recovery in elderly patients after lung cancer surgery was not related to their health-related QOL recoveries [4]. One of the possible reasons for the inconsistent results is that the effect of physical activity on QoL is indirect. Our results confirmed the possibility and an indirect effect between QoL with physical activities were observed.

Cardiorespiratory fitness is determined mainly by aerobic physical activity, and CRF is strong associated with the physical dimensions of health-related QoL [16]. In our study, CRF (VT and $\mathrm{VO}_{2 \max }$ ) was positively associated with the physical dimensions except for the pain of QoL, and CRF had a direct effect on QoL. In fact, much evidence showed that there was a strong correlation between 6MWT [6], pulmonary function [4], and CRF. Our results clearly showed that the relationship between physical activity, pulmonary function, and QoL was significantly mediated by CRF in patients with lung cancer resection. This result was similar to the previous works that CRF mediated the effects of 12-week aerobic exercise on general fatigue in a woman with systemic lupus erythematosus [17]. As a mediator, CRF also affected 
the effects of a Mediterranean diet on the mental component summary of QoL. In our study, CRF (VT and $\mathrm{VO}_{2 \max }$ ) was positively associated with 3 out of 4 mental domains of QoL.

In the clinic, QoL in patients with resected lung cancer was poor. Poor QoL means difficulty for these kinds of patients to deal with a range of deficits or limitations related to cognitive, psychosocial, physical, sensory functioning, and other aspects of performance [18]. The results in the present study showed that only 38.5\% of the changes in QoL were due to CRF. Thus, the improving QoL program for the patients with lung resection not only focuses on how to improve CRT, but also pays more attention to other impact factors.

With regard to the limitations of this study, the small number of patients $(n=38)$ means that the study lacked statistical strength. Second, some other factors that could affect QoL in patients with resected lung cancer were not included in our structural equation modelings such as family support and economic level. Third, this was a single-center study.

In conclusion, CRF has a direct effect on the quality of life in patients with resected lung cancer. Furthermore, CRT, as mediated variably, can mediate the relationship between pulmonary function, physical activity, Borg dyspnea, and quality of life. In the future, more attention to improving CRT is needed for improving the quality of life of patients with resected lung cancer.

\section{Declarations}

Funding: the national natural science foundation of China [No. 81972142, No. 81871857].

Conflicts of interest/Competing interests: The authors have no conflicts of interest to declare.

Availability of data and material: All data generated and/or analyzed during the present study are included in this article.

Code availability: N/A

Authors' contributions: XP Li drafted the first version of the manuscript. All authors were involved in all stages of the study design and data collecting, and submission to ethical committee was done by MS Zhang. XP Li and MS Zhang were involved in statistical analysis. All authors read and approved the final version of the manuscript.

Ethics approval: This study was performed according to the declaration of Helsinki and was approved by the Guangdong provincial people's Hospital (No. 2012124H(R2)).

Consent to participate: All patients provided written informed consent before data collection.

Consent for publication: All patients provided written patient consent for publication.

\section{References}


1. Siegel RL, Miller KD, Jemal A. Cancer statistics (2019) CA Cancer J Clin 69(1):7-34. doi: 10.3322/caac. 21551

2. Hong-Lin CK, Liu Q-S, You (2018) Self-efficacy, cancer-related fatigue, and quality of life in patients with resected lung cancer. Eur J Cancer Care (Engl) 27(6):e12934. doi:10.1111/ecc.12934

3. Brocki BC, Westerdahl E, Langer D, Souza DSR, Andreasen JJ (2018) Decrease in pulmonary function and oxygenation after lung resection. ERJ Open Res 4(1):00055-2017.

doi:10.1183/23120541.00055-2017

4. Hiroshi Saito A, Shiraishi H, Nomori H, Matsui K, Yoshida Y, Matsue T, Fujii KK (2020) Impact of age on the recovery of six-minute walking distance after lung cancer surgery: a retrospective cohort study. Gen Thorac Cardiovasc Surg 68(2):150-157. doi:10.1007/s11748-019-01191-7

5. Szeliga E, Czenczek-Lewandowska E, Kontek A, Wolan-Nieroda A, Guzik A, Walicka-Cupryś K (2019) Evaluation of the quality of life after surgical removal of lung cancer. Adv Respir Med 87(1):14-19. doi:10.5603/ARM.a2019.0003

6. Olga Marieke de Vries, Johansen H, Svein Otto Fredwall (2021) Physical fitness and activity level in Norwegian adults with achondroplasia. Am J Med Genet 185(4):1023-1032. doi:10.1002/ajmg.a.62055

7. Engberg E, Tikkanen HO, Koponen A, Hägglund H, Kukkonen-Harjula K, Tiitinen A, Peltonen JE, Pöyhönen-Alho M (2018) Cardiorespiratory fitness and health-related quality of life in women at riskfor gestational diabetes. Scand J Med Sci Sports 28(1):203-211. doi:10.1111/sms.12896

8. Duc Ha AL, Ries, Peter J, Mazzone SM, Lippman, Mark M, Fuster (2018) Exercise capacity and cancer-specific quality of life following curative intent treatment of stage I-IIIA lung cancer. Support Care Cancer 26(7):2459-2469. doi:10.1007/s00520-018-4078-4

9. Ware JE Jr, Gandek B (1998) Overview of the SF-36 Health Survey and the International Quality of Life Assessment (IQOLA) Project. J Clin Epidemiol 51:903-912. doi:10.1016/s0895-4356(98)00081$\mathrm{x}$

10. Miller MR, Hankinson J, Brusasco V, Burgos F, Casaburi R, Coates A, Crapo R, Enright P, van der Grinten CP, Gustafsson P, Jensen R, Johnson DC, Maclntyre N, McKay R, Navajas D, Pedersen OF, Pellegrino R, Viegi G, Wanger J, ATS/ERS Task Force (2005) Standardisation of spirometry. Eur Respir J 26(2):319-338. doi:10.1183/09031936.05.00034805

11. Brunelli A, Socci L, Refai M, Salati M, Xiumé F, Sabbatini A (2007) Quality of life before and after major lung resection for lung cancer: a prospective follow-up analysis. Ann Thorac Surg 84(2):410416. doi:10.1016/j.athoracsur.2007.04.019

12. Ari Mänttäri J, Suni H, Sievänen $P$, Husu H, Vähä-Ypyä H, Valkeinen $K$, Tokola, Tommi Vasankari (2018) Six-minute walk test: a tool for predicting maximal aerobic power (VO2max) in healthy adults. Physiol Funct Imaging. doi:10.1111/cpf.12525

13. Preacher KJ, Hayes AF (2008) Asymptotic and resampling strategies for assessing and comparing indirect effects in multiple mediator models. Behav Res Methods 40(3):879-891 
14. Wolkove N, Dajczman E, Colacone A, Kreisman H (1989) The relationship between pulmonary function and dyspnea in obstructive lung disease. Chest 96(6):1247-1251. doi:10.1378/chest.96.6.1247

15. Janet L, Larson MK, Covey, Susan Corbridge (2002) Inspiratory muscle strength in chronic obstructive pulmonary disease. AACN Clin Issues 13(2):320-332. doi:10.1097/00044067200205000-00015

16. Olga Marieke de Vries, Johansen H, Svein Otto Fredwall (2021) Physical fitness and activity level in Norwegian adults with achondroplasia. Am J Med Genet A 185(4):1023-1032. doi:10.1002/ajmg.a.62055

17. Blanca G-C, José Antonio Vargas-Hitos, Pablo Morillas-de-Laguno, Antonio Rosales-Castillo, Sergio Sola-Rodríguez, José Luis Callejas-Rubio, José Mario Sabio, Alberto Soriano-Maldonado. (2020). Effects of 12-week aerobic exercise on patient-reported outcomes in women with systemic lupus erythematosus. Disabil Rehabil 1-9. doi: 10.1080/09638288.2020.1808904

18. Ping Yang AL, Cheville JA, Wampfler YI, Garces A, Jatoi MM, Clark SD, Cassivi DE, Midthun RS, Marks M-C, Aubry, Scott H, Okuno, Brent A, Williams FC, Nichols, Victor F, Trastek H, Sugimura L, Sarna, Mark S, Allen C, Deschamps, Jeff A, Sloan (2012) Quality of life and symptom burden among long-term lung cancer survivors. J Thorac Oncol 7(1):64-70. doi:10.1097/JT0.0b013e3182397b3e

\section{Figures}

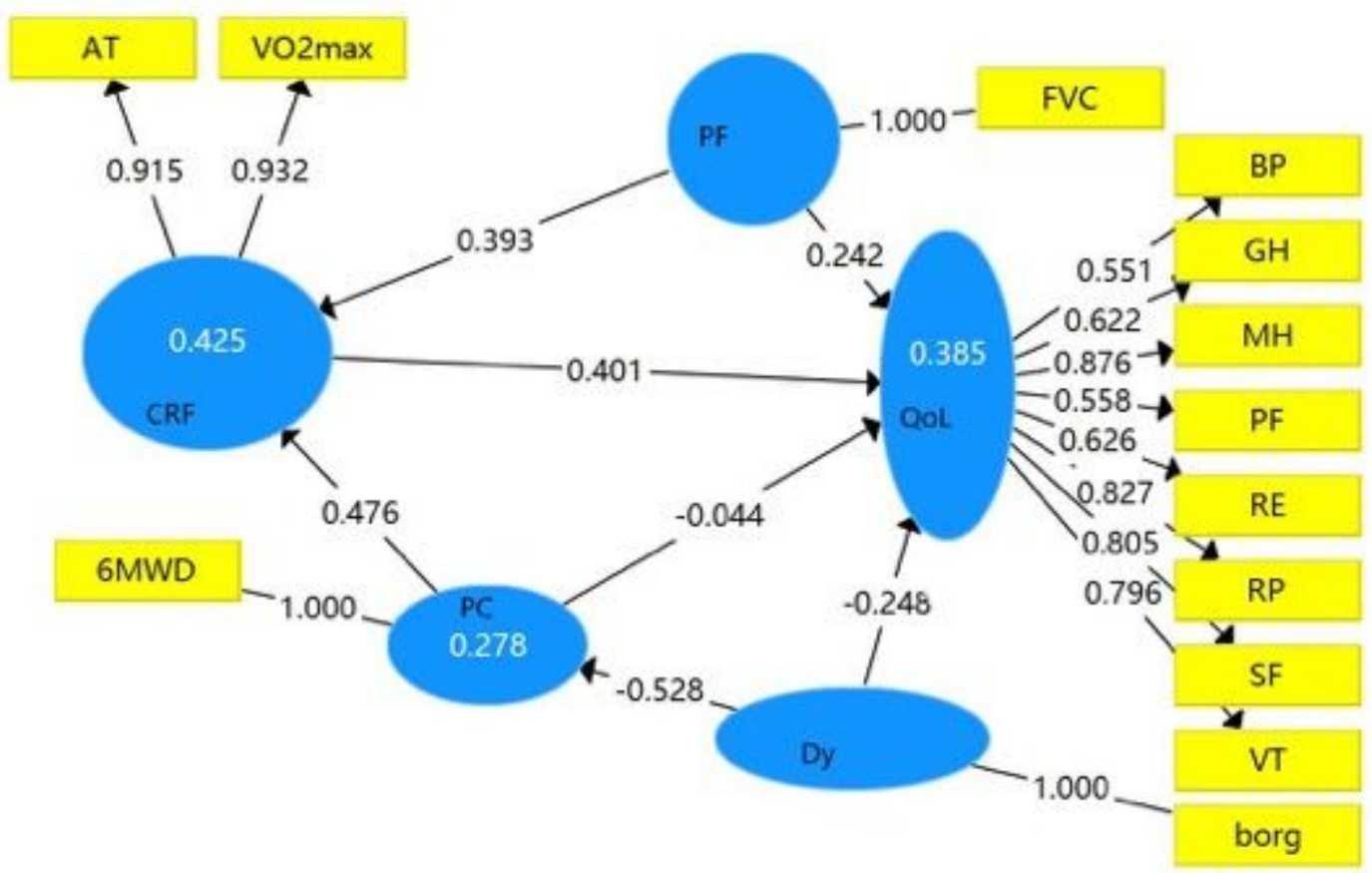

Figure 1 
Structural model: Exploring the paths model to quality of life. Dy, dyspnea; PC, physical capacity; CRF, Cardiorespiratory fitness; PF, pulmonary function; QoL, quality of life

A: Basic model

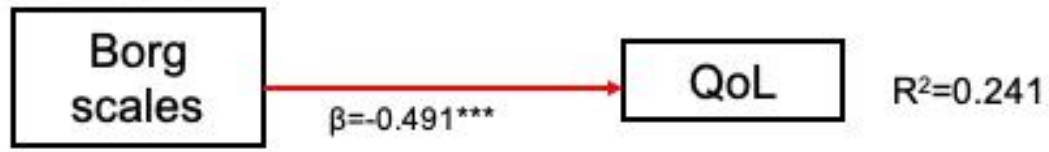

\section{B: Mediation model (indirect effect)}
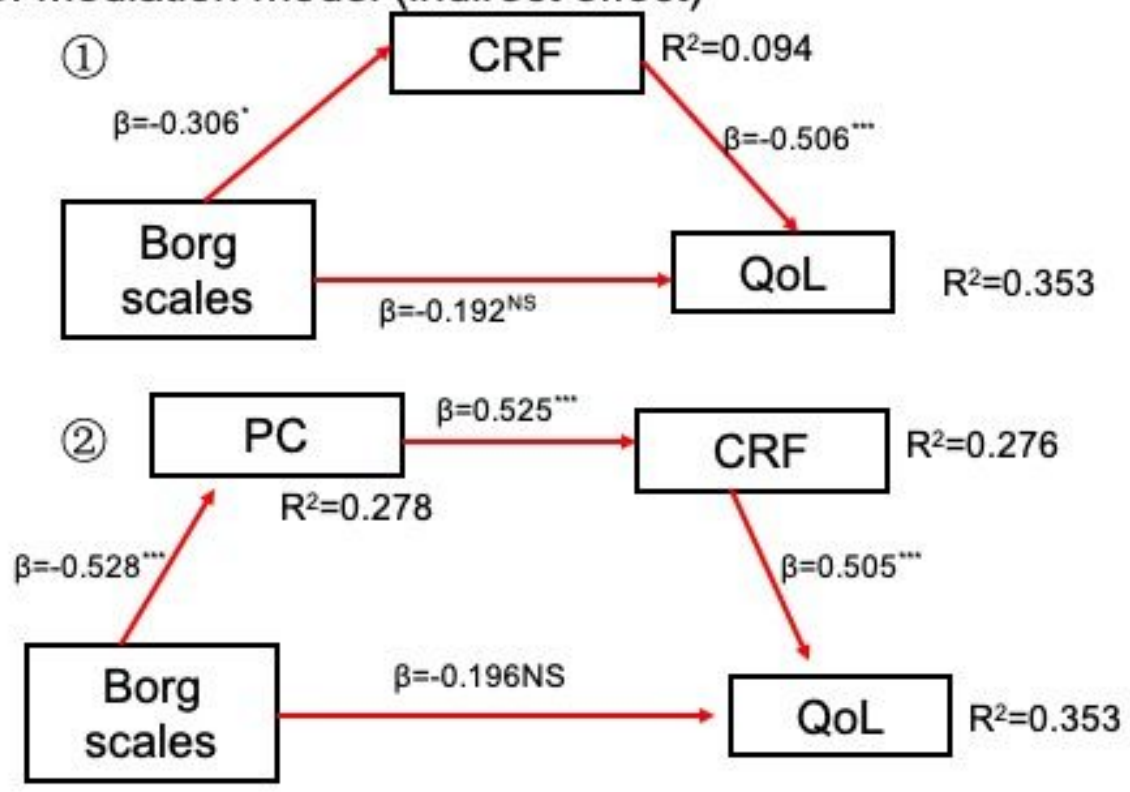

${ }^{\star} p<0.05 ;{ }^{* \star} p<0.01 ;{ }^{* \star *} p<0.001 ; N S=$ not significant

PC, physical capacity; CRF,Cardiorespiratory fitness; QoL, quality of life

\section{Figure 2}

Mediating effect of Borg scale on quality of life, via PC and CRF

\section{Supplementary Files}

This is a list of supplementary files associated with this preprint. Click to download.

- Supplementaryfigure1.jpg

- Supplementaryfigure2.jpg 